\title{
A common polymorphism in NR1H2 (LXRbeta) is associated with preeclampsia
}

\author{
Kevin Mouzat ${ }^{1}$, Eric Mercier ${ }^{2}$, Anne Polge ${ }^{1}$, Alexandre Evrard ${ }^{1}$, Silvère Baron ${ }^{3}$, Jean-Pierre Balducchi ${ }^{4}$, \\ Jean-Paul Brouillet ${ }^{1}$, Serge Lumbroso ${ }^{1+}$ and Jean-Christophe Gris $^{2+}$
}

\begin{abstract}
Background: Preeclampsia is a frequent complication of pregnancy and a leading cause of perinatal mortality. Both genetic and environmental risk factors have been identified. Lipid metabolism, particularly cholesterol metabolism, is associated with this disease. Liver $X$ receptors alpha (NR1H3, also known as LXRalpha) and beta (NR1H2, also known as LXRbeta) play a key role in lipid metabolism. They belong to the nuclear receptor superfamily and are activated by cholesterol derivatives. They have been implicated in preeclampsia because they modulate trophoblast invasion and regulate the expression of the endoglin (CD105) gene, a marker of preeclampsia. The aim of this study was to investigate associations between the NR1H3 and NR1H2 genes and preeclampsia.
\end{abstract}

Methods: We assessed associations between single nucleotide polymorphisms of NR1H3 (rs2279238 and rs7120118) and NR1H2 (rs35463555 and rs2695121) and the disease in 155 individuals with preeclampsia and 305 controls. Genotypes were determined by high-resolution melting analysis. We then used a logistic regression model to analyze the different alleles and genotypes for those polymorphisms as a function of case/control status.

Results: We found no association between NR1H3 SNPs and the disease, but the NR1H2 polymorphism rs2695121 was found to be strongly associated with preeclampsia (genotype C/C: adjusted odds ratio, 2.05; 95\% Cl, 1.04-4.05; $p=0.039$ and genotype T/C: adjusted odds ratio, $1.85 ; 95 \% \mathrm{Cl}, 1.01-3.42 ; p=0.049$ ).

Conclusions: This study provides the first evidence of an association between the NR1H2 gene and preeclampsia, adding to our understanding of the links between cholesterol metabolism and this disease.

\section{Background}

Preeclampsia (PE) is a frequent complication of the second half of pregnancy and is one of the leading causes of maternal perinatal mortality and morbidity [1]. This condition, affecting 2.5 to $3 \%$ of pregnant women is defined by gestational hypertension accompanied by proteinuria $[2,3]$. Many risk factors have been described, including, in particular, cardiovascular risks, such as diabetes mellitus and high body mass index $[4,5]$. Cholesterol metabolism may also contribute to the pathogenesis of preeclampsia. Indeed, high total cholesterol and LDL (low density lipoprotein)-cholesterol levels are significantly associated with this disease [6]. Moreover, it has

\footnotetext{
* Correspondence: kevin.mouzat@chu-nimes.fr

+ Contributed equally

'Department of Biochemistry, Nimes University Hospital, F-30029 Nîmes

Cedex 9, France

Full list of author information is available at the end of the article
}

been shown that a familial history of PE almost triples the risk of a woman developing this disease, consistent with the involvement of genetic factors [4]. Many risk factors have been described, but the molecular mechanisms underlying this disease remain unclear. Liver $\mathrm{X}$ receptors (LXRs) NR1H3 and NR1H2, more commonly known as LXRalpha and LXRbeta, play a key role in cholesterol metabolism $[7,8]$. They belong to a subclass of nuclear receptors that form obligate heterodimers with 9-cis retinoic acid receptors (RXR). They also bind to and are activated by naturally occurring oxidized forms of cholesterol, known as oxysterols, the intracellular concentrations of which are directly correlated with cholesterol concentration [9]. Knockout mice deficient in oxysterol synthesis pathways are unable to induce LXRtarget genes in response to dietary cholesterol, demonstrating that these nuclear receptors are endogenous receptors for oxysterols [10]. Upon ligand binding, they 
activate the transcription of many genes involved essentially in lipid metabolism, cholesterol metabolism in particular. Thus, by stimulating the cellular efflux and hepatic reverse transport of cholesterol and inhibiting its endogenous synthesis, they act as hypocholesterolemic factors [11]. LXRs may therefore be considered endogenous cholesterol sensors.

LXRs are promising candidates in investigations of the molecular causes of PE. It is now widely accepted that PE results from placentation defects. Indeed, any defect in trophoblast development or differentiation can result in PE [12]. LXRs are expressed in human placenta at various stages of pregnancy, right until term [13], and their expression increases during pregnancy [14]. In addition to their potential role in regulating placental lipid metabolism, LXRbeta has recently been shown to control trophoblast invasion in vitro [15]. Furthermore, we have also shown that ENG, encoding endoglin (CD105), a protein controlling placental angiogenesis [16], is a direct target of LXRalpha [17]. Soluble ENG is a marker of PE, and its serum concentration is tightly correlated with disease severity.

Single nucleotide polymorphisms (SNP) of the NR1H3 (LXRalpha) and NR1H2 (LXRbeta) genes have recently been associated with many metabolic indicators and conditions, including circulating total, LDL and HDL (High Density Lipoprotein)-cholesterol levels for NR1H3 [18-20], and type 2 diabetes mellitus and obesity for both $N R 1 H 3$ and NR1H2 [21-24]. Based on these previous studies, we selected two SNPs (rs2279238 and rs7120118) in the NR1H3 gene, mapping to chromosome 11p11.2 and two SNPs (rs2695121 and rs35463555) in the NR1H2 gene, mapping to chromosome 19q13.3 for study. Rs2279238, rs2695121 and rs35463555 have been reported to be associated with obesity [22]; rs2279238 is also associated with risk factors for type 2 diabetes mellitus [23]. Finally, rs7120118 was chosen for study because it has been shown to be associated with HDL-cholesterol levels [20].

In a case-control study of 155 preeclamptic and 305 normal pregnancies based on a powerful high-resolution melting curve analysis technique, we showed that the NR1H2 polymorphism rs2695121 was strongly associated with PE. These findings suggest that further studies of the role of LXRbeta in the pathogenesis of this disease will be of interest. By contrast, we found no significant association between the NR1H3 SNPs (rs2279238 and rs7120118) and PE.

\section{Methods}

\section{Ethics statement}

This study was approved by the local ethics committee (CPP: Comité de Protection des Personnes Sud Méditerranée III). We recruited 155 patients between December 1997 and July 2002. Both cases and controls gave written informed consent for participation in the study. The clinical investigation was performed in accordance with the Helsinki Declaration and its amendments.

\section{Patients and controls}

All the patients and controls were primiparous.

Patients were referred to the outpatient clinic of the Gynecology and Obstetrics Department or to the Hematology Laboratory, University Hospital of Nîmes, between December 1997 and July 2002, for thrombophilia screening and relevant investigations.

The inclusion criterion for the patients was preeclampsia during a natural pregnancy, defined as gravidic hypertension (systolic blood pressure $[\mathrm{BP}]>140 \mathrm{~mm} \mathrm{Hg}$, diastolic $\mathrm{BP}>90 \mathrm{~mm} \mathrm{Hg}$, a rise in systolic $\mathrm{BP}>30 \mathrm{~mm}$, or a rise in diastolic $\mathrm{BP}>15 \mathrm{~mm} \mathrm{Hg}$ on at least two measurements 6 hours apart) after 20 weeks, associated with significant proteinuria (> $300 \mathrm{mg} / 24 \mathrm{~h}$ ). Thirty-six of the 155 preeclampsia patients had developed a severe form according to current definitions, before 34 weeks of gestation in nine cases. There were 11 cases of HELLP (hemolysis, elevated liver enzymes, low platelets) syndrome and two cases of eclampsia. We were unable to analyze severity subgroups, due to the small number and heterogeneity of the severe preeclampsia cases.

The 305 controls were women from the NOHA First Cohort, with uneventful pregnancies [25].

Data were collected for putative clinical predictors of preeclampsia: age, body mass index (BMI), smoking (defined as at least one cigarette per day), gravidity (evaluating the number of previous miscarriages), ethnicity, diabetes mellitus, pre-existing arterial hypertension (defined as the use of hypertensive medication, a systolic blood pressure of at least $140 \mathrm{~mm} \mathrm{Hg}$ or a diastolic blood pressure of at least $90 \mathrm{~mm} \mathrm{Hg}$ on two readings taken in a supine position $5 \mathrm{~min}$ apart, and on two separate occasions) and maternal history of preeclampsia.

\section{SNP genotyping}

Genomic DNA was extracted from $10 \mathrm{ml}$ of peripheral maternal whole blood collected into tubes containing EDTA (ethylenediaminetetraacetic acid) and sodium chloride, as described elsewhere [26]. The SNPs chosen for study were genotyped, as previously described [27]. Briefly, $10 \mathrm{ng}$ of genomic DNA was subjected to PCR (polymerase chain reaction) amplification with LightCycler $^{\circledR} 480$ High-Resolution Melting Master Mix (Roche Diagnostics, Meylan, France), using a touchdown protocol as follows: initial denaturation at $95^{\circ} \mathrm{C}$ for 10 minutes then 50 cycles of denaturation at $95^{\circ} \mathrm{C}$ for 10 seconds; annealing at temperatures decreasing from $70^{\circ} \mathrm{C}$ to $60^{\circ} \mathrm{C}$ (step size: $0.5^{\circ} \mathrm{C} /$ cycle) for 20 seconds and elongation at $72^{\circ} \mathrm{C}$ for 20 seconds. High-resolution melting curve data were obtained by monitoring the decrease in fluorescence from 
Table 1 Sequence primers used for high-resolution melting curve analyses

\begin{tabular}{|c|c|c|}
\hline SNP (gene) & $5^{\prime}-3^{\prime}$ sequences & Size of the amplicon (bp) \\
\hline \multirow[t]{2}{*}{ rs2279238 (NR1H3) } & Fw: GAGAGCGTTGAAGCACTTTC & 140 \\
\hline & Rev: GCTCAGAACATTGTAGTGGAAG & \\
\hline \multirow[t]{2}{*}{ rs7120118 (NR1H3) } & Fw: CCTTTGGCACTTGTAGACTCAT & 159 \\
\hline & Rev: GGAGGGGAGGAGACTTGAC & \\
\hline \multirow[t]{2}{*}{ rs35463555 (NR1H2) } & FW: CAGGAAGGAAGTGACAGAGACA & 111 \\
\hline & Rev: CCATCGTTTGAGATTGTGGA & \\
\hline \multirow[t]{2}{*}{ rs2695121 (NR1H2) } & FW: GGCAGGTCTTGTTAGAAGGA & 171 \\
\hline & Rev: AATACAGGGGATTGAGAGCC & \\
\hline
\end{tabular}

$75^{\circ} \mathrm{C}$ to $95^{\circ} \mathrm{C}$ at a rate of 25 acquisitions per degree Celsius on a LightCycler ${ }^{\circledR} 480$ apparatus (Roche Diagnostics). The sequences of the primers used for PCR are given in table 1. Fluorescence data were visualized by normalization, temperature-shifting and difference plotting, and were then analyzed with LightCycler ${ }^{\circledR}$ Gene Scanning software (Roche Diagnostics). Melting curve analysis for rs2279238 and rs7120118 generated three distinct profiles corresponding to the three possible genotypes (frequent homozygous, heterozygous and rare homozygous, according to the NCBI SNP database (dbSNP; human build 132)). The identification of rare homozygous genotypes for rs2695121 and rs35463555 was made possible by diluting each sample with a known frequent homozygous genotype (2 ng) before PCR, thus generating a heterozygous profile, according to the kit manufacturer's recommendations. Genotyping results were confirmed by directly sequencing the PCR products of $10 \%$ of the samples with the primers used for PCR. PCR products were purified with the Agencourt AMPure XP kit (Beckman Coulter Genomics, Grenoble, France), according to the manufacturer's recommendations. Sequencing reactions were carried out with the BigDye ${ }^{\circledR}$ Terminator v1.1 Cycle Sequencing Kit (Applied Biosystems, Courtaboeuf, France) and products were purified with the CleanSEQ kit (Beckman Coulter Genomics), according to the manufacturer's instructions. The purified products were then resolved on a $3130 \mathrm{xl}$ Genetic Analyzer (Applied Biosystems).

\section{Statistical analysis}

Deviation from Hardy-Weinberg equilibrium (HWE) was assessed with DeFinetti software (T.F. Wienker and T.M. Strom, unpublished data, http://ihg.gsf.de/cgi-bin/hw/ hwa1.pl). The frequencies of particular alleles and genotypes in cases and controls were assessed by $\chi^{2}$ analysis (Statview software 5.0, SAS Institute). Analyses of the pairwise linkage disequilibrium ( $D^{\prime}$ and $r^{2}$ ) between the markers in each genomic region and haplotype analysis were carried out with Haploview 4.2 Software [28].

The putative predictors of preeclampsia - the clinical factors listed above and the four polymorphisms studied were evaluated in women, initially by univariate analysis and then by multivariate logistic regression analysis. We calculated the corresponding crude odds ratio (cOR) and its 95\% confidence interval (95\% CI) and then the adjusted odds ratio (aOR) and its 95\% CI. Variables for multivariate models were selected in a stepwise manner, beginning with all the variables for which $p<0.25$ in univariate models as potential predictors, with final adjustment for all variables for which $p<0.25$ in the univariate models.

\section{Results}

\section{Characteristics of the participants}

The characteristics of controls and patients at diagnosis are presented in table 2 . There were no significant differences in age, ethnicity or percentage of smokers between the two groups. Body mass index, and the percentages of women with two previous spontaneous miscarriages, diabetes mellitus, pre-existing arterial hypertension or a maternal history of PE were significantly higher in the PE group than in controls.

\section{Polymorphisms and risk of preeclampsia}

Tables 3 and 4 show the allelic and genotypic frequencies, respectively, for cases and controls. Genotyping of the SNPs in the NR1H3 (LXRalpha) gene revealed that the T allele of rs2279238 was found in $14.10 \%$ of controls and $11.69 \%$ of cases; the $C$ allele of rs7120118 was found in $25.74 \%$ of controls and $23.87 \%$ of cases. For the NR1H2 (LXRbeta) gene, the A allele of rs35463555 was found in $27.38 \%$ of controls and $32.90 \%$ of cases. The allelic frequencies of these three SNPs did not significantly differ between cases and controls. By contrast, the $\mathrm{C}$ allele of rs 2695121 was found in $54.43 \%$ of controls and $64.84 \%$ of cases $(p=0.003)$. None of the distributions for the alleles and genotypes of the SNPs analyzed deviated from HardyWeinberg equilibrium in either cases or controls (data not shown).

We used these data to generate logistic regression models for each of the SNPs genotyped (Table 5). Univariate analyses indicated that the genotype distributions of NR1H3 (LXRalpha) SNPs (rs2279238 and rs7120118) did not differ significantly between cases and controls. The risk of PE in carriers of homozygous and heterozygous 
Table 2 Clinical characteristics of controls and patients

\begin{tabular}{|c|c|c|c|c|c|}
\hline Characteristics & Controls $(\mathrm{N}=305)$ & Patients $(\mathrm{N}=155)$ & $p$-value $^{a}$ & COR $(95 \% \mathrm{Cl})$ & $p$-value ${ }^{b}$ \\
\hline Age & $29 \pm 7(23-36)$ & $30 \pm 7(23-37)$ & 0.103 & $1.04(0.99-1.09)$ & 0.099 \\
\hline BMl & $\begin{array}{l}22.46 \pm 2.60 \\
(16.32-28.50)\end{array}$ & $\begin{array}{l}22.80 \pm 2.45 \\
(17.74-29.40)\end{array}$ & 0.063 & $1.12(1.02-1.22)$ & 0.021 \\
\hline Smoking & $13(4.26)$ & $3(1.94)$ & 0.309 & $0.44(0.12-1.58)$ & 0.210 \\
\hline Gravidity: & & & 0.076 & & \\
\hline 1 & $259(84.92)$ & $121(78.06)$ & & 1 & \\
\hline 2 & $35(11.48)$ & $21(13.55)$ & & $1.28(0.72-2.30)$ & 0.400 \\
\hline 3 & $11(3.61)$ & $13(8.39)$ & & $2.53(1.10-5.81)$ & 0.029 \\
\hline Ethnicity: & & & 0.690 & & \\
\hline Caucasian & $291(95.41)$ & 145 (93.55) & & 1 & \\
\hline African & $8(2.62)$ & $6(3.87)$ & & $1.51(0.51-4.42)$ & 0.457 \\
\hline Asian & $6(1.97)$ & $4(2.58)$ & & $1.34(0.37-4.82)$ & 0.656 \\
\hline Diabetes Mellitus & $4(1.31)$ & $7(4.52)$ & 0.071 & $3.56(1.03-12.4)$ & 0.046 \\
\hline Pre-existing arterial hypertension & $8(2.62)$ & $12(7.74)$ & 0.021 & $3.12(1.25-7.79)$ & 0.015 \\
\hline Maternal PE antecedent & $10(3.28)$ & $13(8.39)$ & 0.032 & $2.70(1.16-6.31)$ & 0.022 \\
\hline
\end{tabular}

Age and $\mathrm{BMI}$ are presented as medians \pm interquartile range and ranges are indicated in brackets. For nominal values, percentages are indicated in brackets. ${ }^{a}$ : Mann-Whitney test for continuous variables; ${ }^{\text {b. }}$ chi-square test for nominal variables. Abbreviations: BMl, body mass index; cOR, crude odds ratio; $95 \%$ Cl, $95 \%$ confidence interval.

variant alleles for these two SNPs was similar to that in individuals homozygous for the wild-type alleles. Interestingly, both NR1H2 (LXRbeta) SNPs (rs35463555 and rs2695121) were found to be significantly associated with preeclampsia, which was more frequent in individuals homozygous for the mutated alleles. After adjustment for putative clinical predictors of preeclampsia - pre-existing arterial hypertension, BMI, maternal history of $\mathrm{PE}$, gravidity, diabetes mellitus, age and smoking - NR1H2 SNP rs2695121 continued to be an independent risk factor for preeclampsia in multivariate logistic regression analysis (table 6). This significance was retained for the homozygous mutated allele $\mathrm{C}$, unmasked for the heterozygous allele $\mathrm{C}$ and lost for the NR1H2 SNP rs35463555.

\section{Haplotype analysis}

By studying the combinations of the two polymorphisms in each gene, we identified three common haplotypes for the
NR1H3 (LXRalpha) gene and four for the NR1H2 (LXRbeta) gene (table 7). None of NR1H3 haplotypes was associated with PE. The two haplotypes of the NR1H2 gene (GT and AC) were associated with preeclampsia $(p=0.009$ and $p=0.026$, respectively). Haploblock analysis revealed that the two markers within each of the genes studied were in linkage disequilibrium (Additional file 1, Figure S1).

\section{Discussion}

This is the first study to investigate the association of the NR1H2 (LXRbeta) gene with preeclampsia. We report here a new genetic association between the SNP rs2695121, in the NR1H2 gene, and preeclampsia. By contrast, the two SNPs within the NR1H3 (LXRalpha) gene studied, rs2279238 and rs7120118, were not identified as independent risk factors for this disease.

The four SNPs studied here were chosen on the basis of previously identified genetic associations with other

Table 3 Allelic counts and frequencies of studied polymorphisms

\begin{tabular}{|c|c|c|c|c|c|}
\hline SNP (gene) & SNP & Allele & Controls & Cases & $p$-value \\
\hline \multirow[t]{4}{*}{ LXRalpha (NR1H3) } & rs2279238 & C & $524(85.90)$ & 272 (88.31) & \\
\hline & & $T$ & $86(14.10)$ & 36 (11.69) & 0.310 \\
\hline & rs7120118 & $T$ & $453(74.26)$ & $236(76.13)$ & \\
\hline & & C & $157(25.74)$ & $74(23.87)$ & 0.648 \\
\hline \multirow[t]{4}{*}{ LXRbeta (NR1H2) } & rs35463555 & G & $443(72.62)$ & 208 (67.10) & \\
\hline & & $\bar{A}$ & $167(27.38)$ & $102(32.90)$ & 0.082 \\
\hline & rs2695121 & $T$ & $278(45.57)$ & $109(35.16)$ & \\
\hline & & $\mathrm{C}$ & $332(54.43)$ & $201(64.84)$ & 0.003 \\
\hline
\end{tabular}

The table presents total counts for each allele. The percentages of the alleles in each group (controls or cases) are indicated in brackets. A difference in allele distribution between the two groups was considered significant if the $p$-value was less than 0.05 . 
Table 4 Genotypic counts and frequencies of the studied polymorphisms

\begin{tabular}{|c|c|c|c|c|}
\hline Gene & SNP & Genotype & Controls & Cases \\
\hline \multirow[t]{6}{*}{ LXRalpha (NR1H3) } & & $\mathrm{C} / \mathrm{C}$ & $225(73.77)$ & $119(77.27)$ \\
\hline & rs2279238 & $C / T$ & $74(24.26)$ & $34(22.08)$ \\
\hline & & $\mathrm{T} / \mathrm{T}$ & $6(1.97)$ & $1(0.65)$ \\
\hline & & $\mathrm{T} / \mathrm{T}$ & $164(53.77)$ & $87(56.13)$ \\
\hline & rs7120118 & $\mathrm{T} / \mathrm{C}$ & $125(40.98)$ & $62(40.00)$ \\
\hline & & $\mathrm{C} / \mathrm{C}$ & $16(5.25)$ & $6(3.87)$ \\
\hline \multirow[t]{6}{*}{ LXRbeta (NR1H2) } & & $\mathrm{G} / \mathrm{G}$ & $157(51.48)$ & $74(47.74)$ \\
\hline & rs35463555 & $\mathrm{G} / \mathrm{A}$ & $129(42.30)$ & $60(38.71)$ \\
\hline & & $\mathrm{A} / \mathrm{A}$ & $19(6.23)$ & $21(13.55)$ \\
\hline & & $\mathrm{T} / \mathrm{T}$ & 70 (22.95) & $21(13.55)$ \\
\hline & rs2695121 & $\mathrm{T} / \mathrm{C}$ & $138(45.25)$ & $67(43.23)$ \\
\hline & & $\mathrm{C} / \mathrm{C}$ & $97(31.80)$ & $67(43.23)$ \\
\hline
\end{tabular}

The table presents total counts for each genotype. The percentages of the genotypes in each group (control or cases) are indicated in brackets.

physiological or physiopathological conditions. The rs2279238 SNP (NM_005693.2:c.297C > T $(p .=)$ ) is located within exon 4 of the NR1H3 gene (Figure 1A), but the nucleotide variation is synonymous, resulting in a protein sequence identical to that of the wild type. We also used four splice site prediction programs (SpliceSiteFinder-like, MaxEntScan, NNSPLICE and Human Splicing Finder) in Alamut 2.0 Software (Interactive Biosoftware, Mont-Saint-Aignan, France). These programs were unable to detect any clear splicing site modifications induced by the SNP within the gene. The SNP did not result in a predicted miRNA (microRNA) binding site (identified by MicroCosm Targets software) either. It is thus highly unlikely that this SNP was functional at the molecular level. Similarly, rs7120118 (NM_005693.2:c.988+2721T > C), which is located within an intron, would be unlikely to affect protein sequence and/or activity. The NR1H2 SNP rs2695121 (NM_007121.4:c.-19-103T > C), which was found to be associated with preeclampsia, is an intronic

Table 5 Logistic regression analysis of the associations between LXRalpha or LXRbeta SNPs and preeclampsia (univariate analysis)

\begin{tabular}{|c|c|c|c|c|c|}
\hline Gene & SNP & Genotype & COR & $95 \% \mathrm{Cl}$ & $p$-value \\
\hline \multirow[t]{4}{*}{ LXRalpha (NR1H3) } & rs2279238 & $\mathrm{C} / \mathrm{T}$ & 0.87 & $0.55-1.38$ & 0.551 \\
\hline & & $\mathrm{T} / \mathrm{T}$ & 0.32 & $0.04-2.65$ & 0.288 \\
\hline & rs7120118 & $\mathrm{T} / \mathrm{C}$ & 0.94 & $0.63-1.40$ & 0.742 \\
\hline & & $\mathrm{C} / \mathrm{C}$ & 0.71 & $0.27-1.87$ & 0.485 \\
\hline \multirow[t]{4}{*}{ LXRbeta (NR1H2) } & rs35463555 & $\mathrm{G} / \mathrm{A}$ & 0.99 & $0.65-1.49$ & 0.949 \\
\hline & & A/A & 2.35 & $1.19-4.63$ & 0.014 \\
\hline & rs2695121 & $\mathrm{T} / \mathrm{C}$ & 1.62 & $0.92-2.86$ & 0.097 \\
\hline & & $\mathrm{C} / \mathrm{C}$ & 2.30 & $1.29-4.11$ & 0.005 \\
\hline
\end{tabular}

Abbreviations: $\mathrm{COR}$, crude odds ratio; $95 \% \mathrm{Cl}, 95 \%$ confidence interval.
Table 6 Logistic regression model of risk factors for PE (multivariate analysis)

\begin{tabular}{lccc}
\hline Factor & aOR & $\mathbf{9 5 \% ~ C l}$ & $\boldsymbol{p}$-value \\
\hline rs2695121-T/C & 1.85 & $1.01-3.42$ & $\mathbf{0 . 0 4 9}$ \\
\hline rs2695121-C/C & 2.05 & $1.04-4.05$ & $\mathbf{0 . 0 3 9}$ \\
\hline rs35463555-G/A & 0.78 & $0.49-1.24$ & 0.295 \\
\hline rs35463555-A/A & 1.32 & $0.59-2.97$ & 0.500 \\
\hline Pre-existing arterial hypertension & 3.74 & $1.44-9.73$ & $\mathbf{0 . 0 0 7}$ \\
\hline BMl & 1.09 & $0.99-1.21$ & 0.086 \\
\hline Maternal history of PE & 2.35 & $0.95-5.80$ & 0.065 \\
\hline Gravidity: 2 & 1.25 & $0.68-2.30$ & 0.478 \\
\hline Gravidity: 3 & 2.89 & $1.22-6.88$ & $\mathbf{0 . 0 1 6}$ \\
\hline Diabetes mellitus & 3.35 & $0.90-12.5$ & 0.073 \\
\hline Age & 1.05 & $0.99-1.10$ & 0.070 \\
\hline Smoking & 0.66 & $0.18-2.46$ & 0.535 \\
\hline Abbrevin
\end{tabular}

Abbreviations: aOR, adjusted odds ratio; $95 \% \mathrm{Cl}, 95 \%$ confidence interval.

polymorphism that would therefore also be unlikely to affect protein function. This hypothesis was confirmed with the splice site prediction module of Alamut software. However, rs35463555 (NT_011109.16:g.23145898G > A), which was also found to be associated with PE in a univariate logistic regression model, is located within the promoter of the gene, $2 \mathrm{~kb}$ upstream from the transcription start site (Figure 1B). MatInspector analysis (Genomatic Software Suite, München, Germany) showed that this SNP was part of the core sequence of the NR2F (COUP-TFs) orphan nuclear receptor responsive element (data not shown). This program failed to identify this putative sequence when the A allele of the SNP was considered. An siRNA (small interfering RNA) directed against NR2F1 (COUP-TF1) has been shown to downregulate LXR expression and the expression of many LXR target genes in muscle cell cultures [29]. However, the authors of this previous study did not investigate the molecular mechanism underlying this regulation; no direct regulation of NR1H2 by COUP-TFs has thus been demonstrated to date. Moreover, the potential role of COUP-TFs in

Table 7 Haplotypic prevalence of genotyped $\mathrm{NR} 1 \mathrm{H} 3$ and NR1H2 in both groups

\begin{tabular}{lllll}
\hline Gene & Haplotype & Controls (\%) & Cases (\%) & $\boldsymbol{p}$-value \\
\hline LXRalpha (NR1H3) & CT & 0.742 & 0.755 & 0.687 \\
\cline { 2 - 5 } & TC & 0.141 & 0.109 & 0.183 \\
\cline { 2 - 5 } & CC & 0.117 & 0.129 & 0.579 \\
\hline LXRbeta (NR1H2) & GT & 0.433 & 0.343 & 0.009 \\
\cline { 2 - 5 } & GC & 0.293 & 0.328 & 0.280 \\
\cline { 2 - 5 } & AC & 0.251 & 0.320 & 0.026 \\
\cline { 2 - 5 } & AT & 0.023 & 0.009 & 0.126 \\
\hline
\end{tabular}

Haplotype frequencies were compared between cases and controls, in chisquared tests. 


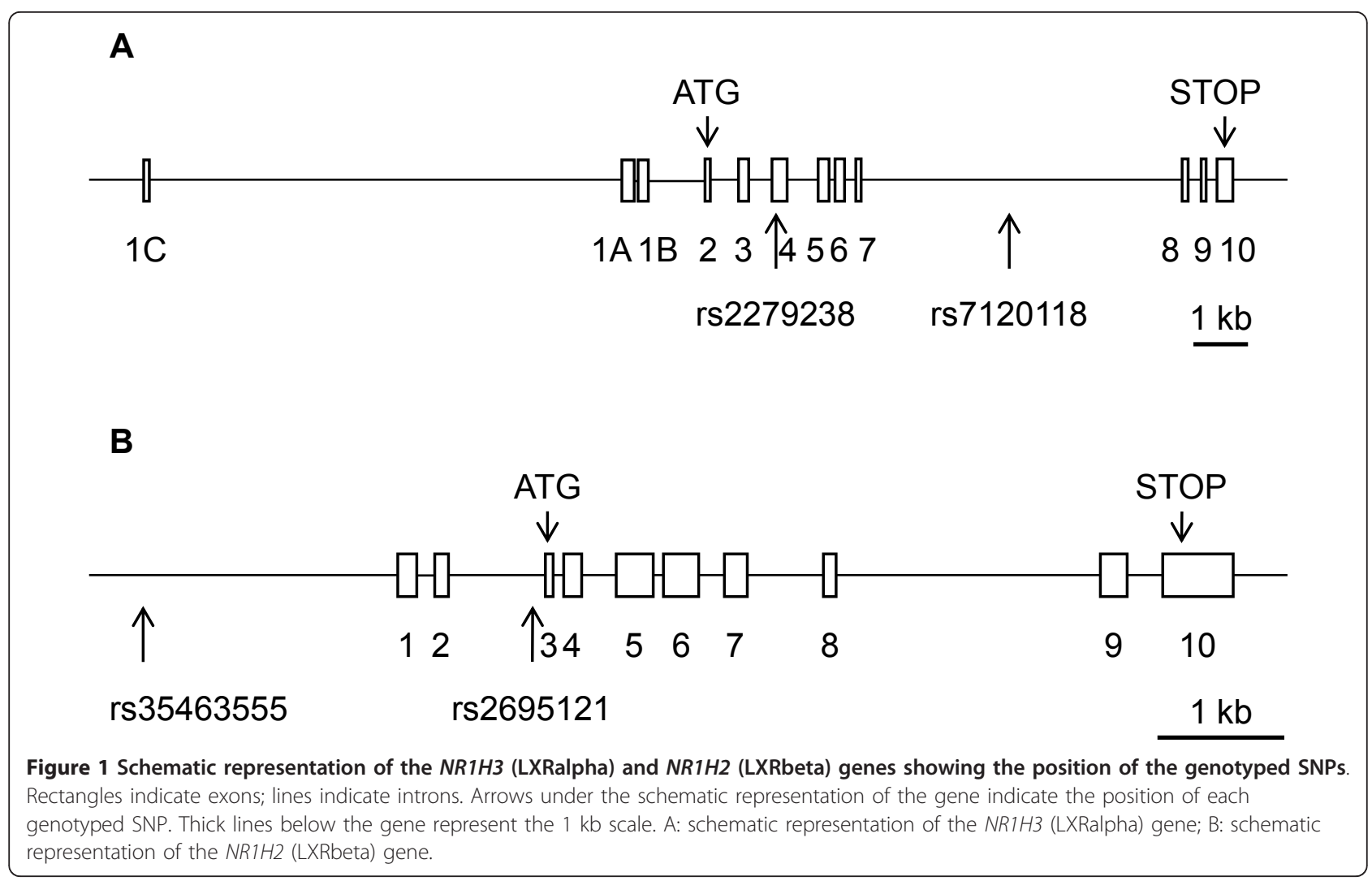

preeclampsia has never been investigated. Based on the results of this bioinformatic simulation, it may be interesting to evaluate the molecular effect of rs35463555 on the transcription of the gene encoding LXRbeta. These predictions suggest that the positive association between the NR1H2 rs2695121 SNP and preeclampsia may result from an indirect association rather than a direct effect of the polymorphism on protein function [30]. Thus, rs2695121 may be in linkage disequilibrium with an unobserved causal locus, which might even be located within another gene in the vicinity of $N R 1 H 2$.

Despite the demonstration of an interesting association between the r2695121 polymorphism in NR1H2 (LXRbeta) and preeclampsia, this study was subject to several limitations. Univariate logistic regression analysis showed that both the SNPs within the NR1H2 gene tested were associated with preeclampsia. However, in a multivariate model including all the clinical cofactors and these two polymorphisms, only rs2695121 remained associated with PE. This association was strengthened by a significant adjusted link between the mutated homozygous but also heterozygous SNP and preeclampsia, but the lack of association between rs35463555 and the diseases warrants further investigation. It may result from there being too few samples in our study, but it could also reflect genetic linkage between the two polymorphisms. We calculated the linkage disequilibrium between the two polymorphisms in our genotyped population and we found evidence of genetic linkage between the two polymorphisms ( $\mathrm{D}^{\prime}=$ $0.85 ; \mathrm{r}^{2}=0.21$; Additional file 1, Figure S1), likely to account, at least in part, for the apparent lack of statistical power in our study.

Many risk factors for preeclampsia have been described. High body mass index, obesity and cholesterolemia are among the most frequently studied and are tightly linked to this disease [6,31]. High total and LDLcholesterol levels have been identified as risk factors for preeclampsia. Our discovery of an association between a polymorphism of NR1H2 (LXRbeta) and PE is therefore of particular interest. Indeed, both LXRs are now widely considered to be major regulators of lipid homeostasis. In recent years, many studies in animals and in vitro models have demonstrated that these nuclear receptors modulate the expression of genes involved in various aspects of the control of cholesterol metabolism (For a review, see [7]). They may act on various pathways: inhibiting de novo cholesterol synthesis by downregulating key enzymes involved in its synthesis, stimulating the cellular efflux of cholesterol by upregulating ATP-binding cassette A1, G1 and G5/G8 (ABCA1, ABCG1 and ABCG5/G8) transporters and inducing the reverse transport of cholesterol by regulating apolipoprotein-encoding genes, such as $A P O E$ 
(apolipoprotein E). Circulating cholesterol has been widely described as a risk factor for preeclampsia, and some APOE alleles have been associated with PE [32]. Our work is thus consistent with recent findings of associations between polymorphisms in the genes encoding LXRalpha and LXRbeta and circulating total, LDL- and HDL-cholesterol concentrations [18-20] and obesity [22,24].

The physiopathological features of preeclampsia seem to result principally from placental ischemia and/or a maternal inflammatory response [1]. Many factors are involved in the development of this disease. In particular, the gene encoding cyclooxygenase-2 (COX-2) has been shown to be overexpressed in the vessels of women with PE [33], and circulating levels of proinflammatory cytokines, such as inteleukin-6 (IL-6), are higher in patients than in controls [34]. In addition to their well known cholesterolemia-lowering effects, LXRs have been implicated in immune processes. Their anti-inflammatory action was first described in 2003 in a study showing that their activation decreased the expression of many proinflammatory factors, including COX-2, iNOS (inducible nitric oxide synthase), IL-1beta (interleukin-1 beta) and IL-6 [35]. Thus, further studies on the role of LXRs in the immune processes associated with preeclampsia will be of particular interest.

Placental angiogenesis also makes a major contribution to preeclampsia. Indeed, defects in the development, differentiation and angiogenesis of the placenta may lead to PE [12]. Defects in signaling by angiogenic factors, such as vascular endothelial growth factor (VEGF), are also frequently observed. Circulating levels of sFLT-1 (soluble VEGF receptor 1) and sENG (soluble endoglin) are high in patients suffering from $\mathrm{PE}$, and may contribute to the pathogenesis of the disease [16,32]. Interestingly, VEGF is a direct target gene of both LXRs [36]. We have also previously reported that ENG is a direct target of LXRalpha in human placental cell cultures [17]. Direct effects of liver $\mathrm{X}$ receptors on the placenta, such as trophoblast invasion [15,37] and syncytialization [38], have recently been suggested. One recent study revealed that the expression of $N R 1 H 3, N R 1 H 2$ and their target gene $A B C A 1$ in JAR cells is stimulated under conditions of low oxygen concentration, mimicking the conditions occurring in preeclampsia [14]. The authors hypothesized that these deregulations might affect cholesterol transport between the mother and the fetus. Overall, these data provide evidence for a functional role for LXRs in the maintenance of placental homeostasis.

Human genetic studies have recently demonstrated associations between polymorphisms of the NR1H3 (LXRalpha) gene and circulating total, LDL- and HDLcholesterol [18-20]. A role for LXRalpha in the pathogenesis of preeclampsia is also supported by our previous work showing that LXRalpha but not LXRbeta induced the promoter of ENG gene [17]. Our work reveals that the NR1H2 (LXRbeta) SNP rs2695121 is a risk factor for preeclampsia. The lack of association between the two tested NR1H3 SNPs and preeclampsia in our work is quite surprising. However, we limited our study to only two polymorphisms of NR1H3 gene, which had already been reported to be associated with physiological and/or pathological conditions. We cannot, on the basis of our results, exclude the possibility that $N R 1 H 3$ is involved in the pathogenesis of preeclampsia, for two major reasons: the statistical power of this study may simply have been too low to pick up a significant association. Moreover, other SNPs, located within the same gene and not in strong linkage disequilibrium with rs2279238 and rs7120118, may be associated with the disease. Indeed, using Tagger implemented in Haploview software with an aggressive tagging method $\left(\mathrm{r}^{2}\right.$ threshold $\left.=0.8\right)$ [39], we showed that our two SNPs covered 91\% of the haplotypic variability of the NR1H3 gene (including $2 \mathrm{~kb}$ on either side of the gene; mean max $\left.r^{2}=0.97\right)$. However, as they did not account for all the variability, it is possible that the absence of association was due to missed haplotypes. Additional studies including more NR1H3 SNPs and/or more samples are therefore required to rule out definitively the existence of an association between this gene and the disease. The two polymorphisms of the NR1H2 gene studied (rs2695121 and rs35463555) have not yet been genotyped in the CEU+TSI populations of the Hapmap project. However, only three SNPs within this gene region have been described in the Hapmap project. These three SNPs are in strong linkage disequilibrium, defining a unique haploblock. As the two TagSNPs proposed by Tagger have never been associated with any physiological or physiopathological condition, we preferred to investigate two potentially functional SNPs described in previous studies, despite the possible lack of haplotypic variability coverage. A deeper replication study, including a larger number of polymorphisms, may facilitate definition of the contribution of NR1H2 to the pathogenesis of preeclampsia. In parallel, it will be interesting to determine the concentration of circulating endoglin in our cohort of patients, to identify possible associations with $\mathrm{NR} 1 \mathrm{H} 2$ genotypes.

\section{Conclusions}

In conclusion, we demonstrate here, for the first time, an association between a polymorphism of the NR1H2 (LXRbeta) gene and preeclampsia. However, caution is required in the clinical interpretation of risk factors [40]. The results of this retrospective pilot study will therefore require confirmation in a secondary prospective study on a set of patients, in which it should be possible to assess the association between the SNPs and disease severity. In 
addition to improving our understanding of the molecular physiopathological features of preeclampsia, this study opens up new possibilities for investigation. In particular, it will be particularly interesting to determine whether LXRbeta could serve as a new marker of the disease. Moreover, as this nuclear receptor is an inducible transcription factor, an understanding of its role in preeclampsia could guide the development of new ligands for the treatment of this disease.

\section{Additional material}

Additional file 1: Figure S1: Linkage disequilibrium between $N R 1 H 3$ and NR1H2 SNPs. The $r^{2}$ values are shown. $D^{\prime}$ was 0.97 and 0.85 between SNPs within the NR1H3 (LXRalpha) and NR1H2 (LXRbeta) genes, respectively.

\section{List of abbreviations used}

95\% Cl: 95\% confidence interval; ABC: ATP-binding cassette; APO: apolipoprotein; BP: blood pressure; COUP-TF: chicken ovalbumin upstream promoter transcription factor; COX-2: cyclooxygenase-2; HDL: high-density lipoprotein; HELLP: hemolysis: elevated liver enzymes: low platelets; HWE: Hardy-Weinberg equilibrium; IL-6: interleukin-6; iNOS: inducible nitric oxide synthase; LDL: low-density lipoprotein; LXR: liver $X$ receptor; ND: not determinable; OR: odds ratio; PE: preeclampsia; RXR: retinoid $\times$ receptor; sENG: soluble endoglin; sFLT-1: soluble VEGF receptor 1; SNP: single nucleotide polymorphism; VEGF: vascular endothelial growth factor.

\section{Acknowledgements}

We thank all the participants, patients and controls who agreed to participate in this study. We thank R. Guirard and E. Douard for excellent technical assistance, Prof. J-M.A. Lobaccaro and Dr. Françoise Caira (UMR CNRS 6247 - Clermont University - INSERM U931) for critically reading the manuscript and for helpful discussions.

\section{Author details}

'Department of Biochemistry, Nimes University Hospital, F-30029 Nîmes Cedex 9, France. '2Department of Hematology, Nimes University Hospital, F30029 Nîmes Cedex 9, France. ${ }^{3}$ GReD Laboratory, UMR CNRS 6247 . Clermont University - INSERM U931, F-63177 Aubière Cedex, France. ${ }^{4}$ Department of Internal Medicine, Nimes University Hospital, F-30029 Nimes Cedex 9, France.

\section{Authors' contributions}

KM, EM, SL, JCG conceived and designed the experiments. KM, EM, JCG acquired the data. KM, JCG analyzed and interpreted the data. EM, AP, AE, $\mathrm{SB}, \mathrm{JPB}^{4}, \mathrm{JPB}^{1}$ contributed to experimental design and revised the manuscript critically. KM, SL, JCG wrote the paper. All authors read and approved the final version of the manuscript.

\section{Competing interests}

The authors declare that they have no competing interests.

Received: 24 May 2011 Accepted: 26 October 2011

Published: 26 October 2011

\section{References}

1. Sibai B, Dekker G, Kupferminc M: Pre-eclampsia. Lancet 2005, 365:785-799.

2. Redman CW, Sargent IL: Latest advances in understanding preeclampsia. Science 2005, 308:1592-1594.

3. Zhang J, Zeisler J, Hatch MC, Berkowitz G: Epidemiology of pregnancyinduced hypertension. Epidemiol Rev 1997, 19:218-232.

4. Duckitt K, Harrington D: Risk factors for pre-eclampsia at antenatal booking: systematic review of controlled studies. Bmj 2005, 330:565.
5. Walsh SW: Obesity: a risk factor for preeclampsia. Trends Endocrinol Metab 2007, 18:365-370.

6. Magnussen EB, Vatten LJ, Lund-Nilsen TI, Salvesen KA, Davey Smith G, Romundstad PR: Prepregnancy cardiovascular risk factors as predictors of pre-eclampsia: population based cohort study. Bmj 2007, 335:978.

7. Viennois E, Pommier AJ, Mouzat K, Oumeddour A, Hajjaji FZ, Dufour J, Caira F, Volle DH, Baron S, Lobaccaro JM: Targeting liver $X$ receptors in human health: deadlock or promising trail? Expert Opin Ther Targets 2011, 15:219-232.

8. Volle DH, Lobaccaro JM: Role of the nuclear receptors for oxysterols LXRs in steroidogenic tissues: beyond the "foie gras", the steroids and sex? Mol Cell Endocrinol 2007, 265-266:183-189.

9. Wong J, Quinn CM, Brown AJ: Synthesis of the oxysterol, 24(S), 25epoxycholesterol, parallels cholesterol production and may protect against cellular accumulation of newly-synthesized cholesterol. Lipids Health Dis 2007, 6:10

10. Chen W, Chen G, Head DL, Mangelsdorf DJ, Russell DW: Enzymatic reduction of oxysterols impairs LXR signaling in cultured cells and the livers of mice. Cell Metab 2007, 5:73-79.

11. Tontonoz $\mathrm{P}$, Mangelsdorf $\mathrm{DJ}$ : Liver $\mathrm{X}$ receptor signaling pathways in cardiovascular disease. Mol Endocrinol 2003, 17:985-993.

12. Huppertz B: Placental origins of preeclampsia: challenging the current hypothesis. Hypertension 2008, 51:970-975.

13. Marceau G, Volle DH, Gallot D, Mangelsdorf DJ, Sapin V, Lobaccaro JM: Placental expression of the nuclear receptors for oxysterols LXRalpha and LXRbeta during mouse and human development. Anat Rec A Discov Mol Cell Evol Biol 2005, 283:175-181.

14. Plosch T, Gellhaus A, van Straten EM, Wolf N, Huijkman NC, Schmidt M, Dunk CE, Kuipers F, Winterhager E: The liver $X$ receptor (LXR) and its target gene $A B C A 1$ are regulated upon low oxygen in human trophoblast cells: a reason for alterations in preeclampsia? Placenta 2010, 31:910-918.

15. Fournier T, Handschuh K, Tsatsaris V, Guibourdenche J, Evain-Brion D: Role of nuclear receptors and their ligands in human trophoblast invasion. $J$ Reprod Immunol 2008, 77:161-170.

16. Venkatesha S, Toporsian M, Lam C, Hanai J, Mammoto T, Kim YM, Bdolah Y, Lim KH, Yuan HT, Libermann TA, et al: Soluble endoglin contributes to the pathogenesis of preeclampsia. Nat Med 2006, 12:642-649.

17. Henry-Berger J, Mouzat K, Baron S, Bernabeu C, Marceau G, Saru JP, Sapin V, Lobaccaro JM, Caira F: Endoglin (CD105) expression is regulated by the liver $\mathrm{X}$ receptor alpha (NR1H3) in human trophoblast cell line JAR. Biol Reprod 2008, 78:968-975.

18. Legry V, Cottel D, Ferrieres J, Chinetti G, Deroide T, Staels B, Amouyel P, Meirhaeghe A: Association between liver $X$ receptor alpha gene polymorphisms and risk of metabolic syndrome in French populations. Int J Obes (Lond) 2008, 32:421-428.

19. Robitaille J, Houde A, Lemieux S, Gaudet D, Perusse L, Vohl MC: The lipoprotein/lipid profile is modulated by a gene-diet interaction effect between polymorphisms in the liver $X$ receptor-alpha and dietary cholesterol intake in French-Canadians. Br J Nutr 2007, 97:11-18.

20. Sabatti C, Service SK, Hartikainen AL, Pouta A, Ripatti S, Brodsky J, Jones CG, Zaitlen NA, Varilo T, Kaakinen M, et al: Genome-wide association analysis of metabolic traits in a birth cohort from a founder population. Nat Genet 2009, 41:35-46.

21. Dahlman I, Nilsson M, Gu HF, Lecoeur C, Efendic S, Ostenson CG, Brismar K, Gustafsson JA, Froguel $P$, Vaxillaire $M$, et al: Functional and genetic analysis in type 2 diabetes of liver $\mathrm{X}$ receptor alleles-a cohort study. BMC Med Genet 2009, 10:27.

22. Dahlman I, Nilsson M, Jiao H, Hoffstedt J, Lindgren CM, Humphreys K, Kere J, Gustafsson JA, Arner P, Dahlman-Wright K: Liver X receptor gene polymorphisms and adipose tissue expression levels in obesity. Pharmacogenet Genomics 2006, 16:881-889.

23. Ketterer C, Mussig K, Machicao F, Stefan N, Fritsche A, Haring HU, Staiger H: Genetic variation within the NR1H2 gene encoding liver $\mathrm{X}$ receptor beta associates with insulin secretion in subjects at increased risk for type 2 diabetes. J Mol Med (Berl) 2011, 89:75-81.

24. Solaas K, Legry V, Retterstol K, Berg PR, Holven KB, Ferrieres J, Amouyel P, Lien $\mathrm{S}$, Romeo J, Valtuena J, et al: Suggestive evidence of associations between liver $\mathrm{X}$ receptor beta polymorphisms with type 2 diabetes mellitus and obesity in three cohort studies: HUNT2 (Norway), MONICA (France) and HELENA (Europe). BMC Med Genet 2010, 11:144. 
25. Lissalde-Lavigne G, Fabbro-Peray P, Cochery-Nouvellon E, Mercier E, RipartNeveu S, Balducchi JP, Daures JP, Perneger T, Quere I, Dauzat M, et al: Factor V Leiden and prothrombin G20210A polymorphisms as risk factors for miscarriage during a first intended pregnancy: the matched case-control 'NOHA first' study. J Thromb Haemost 2005, 3:2178-2184

26. Cochery-Nouvellon $E$, Nguyen $P$, Attaoua $R$, Cornillet-Lefebvre $P$, Mercier $E$, Vitry F, Gris JC: Interleukin 10 gene promoter polymorphisms in women with pregnancy loss: preferential association with embryonic wastage. Biol Reprod 2009, 80:1115-1120.

27. Raynal C, Ciccolini J, Mercier C, Boyer JC, Polge A, Lallemant B, Mouzat K, Lumbroso S, Brouillet JP, Evrard A: High-resolution melting analysis of sequence variations in the cytidine deaminase gene (CDA) in patients with cancer treated with gemcitabine. Ther Drug Monit 2010, 32:53-60.

28. Barrett JC, Fry B, Maller J, Daly MJ: Haploview: analysis and visualization of LD and haplotype maps. Bioinformatics 2005, 21:263-265.

29. Myers SA, Wang SC, Muscat GE: The chicken ovalbumin upstream promoter-transcription factors modulate genes and pathways involved in skeletal muscle cell metabolism. J Biol Chem 2006, 281:24149-24160.

30. Balding DJ: A tutorial on statistical methods for population association studies. Nat Rev Genet 2006, 7:781-791.

31. O'Brien TE, Ray JG, Chan WS: Maternal body mass index and the risk of preeclampsia: a systematic overview. Epidemiology 2003, 14:368-374.

32. Carty DM, Delles C, Dominiczak AF: Novel biomarkers for predicting preeclampsia. Trends Cardiovasc Med 2008, 18:186-194.

33. Shah TJ, Walsh SW: Activation of NF-kappaB and expression of COX-2 in association with neutrophil infiltration in systemic vascular tissue of women with preeclampsia. Am J Obstet Gynecol 2007, 196:48 e41-48.

34. LaMarca BD, Ryan MJ, Gilbert JS, Murphy SR, Granger JP: Inflammatory cytokines in the pathophysiology of hypertension during preeclampsia. Curr Hypertens Rep 2007, 9:480-485.

35. Joseph SB, Castrillo A, Laffitte BA, Mangelsdorf DJ, Tontonoz P: Reciprocal regulation of inflammation and lipid metabolism by liver $\mathrm{X}$ receptors. Nat Med 2003, 9:213-219.

36. Walczak R, Joseph SB, Laffitte BA, Castrillo A, Pei L, Tontonoz P: Transcription of the vascular endothelial growth factor gene in macrophages is regulated by liver X receptors. J Biol Chem 2004, 279:9905-9911.

37. Pavan $L$, Hermouet $A$, Tsatsaris $V$, Therond $P$, Sawamura T, Evain-Brion D, Fournier T: Lipids from oxidized low-density lipoprotein modulate human trophoblast invasion: involvement of nuclear liver $\mathrm{X}$ receptors. Endocrinology 2004, 145:4583-4591.

38. Aye IL, Waddell BJ, Mark PJ, Keelan JA: Oxysterols inhibit differentiation and fusion of term primary trophoblasts by activating liver $\mathrm{X}$ receptors. Placenta 2011, 32:183-191.

39. de Bakker PI, Yelensky R, Pe'er I, Gabriel SB, Daly MJ, Altshuler D: Efficiency and power in genetic association studies. Nat Genet 2005, 37:1217-1223.

40. Ware JH: The limitations of risk factors as prognostic tools. N Engl J Med 2006, 355:2615-2617.

\section{Pre-publication history}

The pre-publication history for this paper can be accessed here: http://www.biomedcentral.com/1471-2350/12/145/prepub

\section{doi:10.1186/1471-2350-12-145}

Cite this article as: Mouzat et al:: A common polymorphism in NR1H2 (LXRbeta) is associated with preeclampsia. BMC Medical Genetics 2011 12:145.

\section{Submit your next manuscript to BioMed Central and take full advantage of:}

- Convenient online submission

- Thorough peer review

- No space constraints or color figure charges

- Immediate publication on acceptance

- Inclusion in PubMed, CAS, Scopus and Google Scholar

- Research which is freely available for redistribution 